九州大学学術情報リポジトリ

Kyushu University Institutional Repository

\title{
Effects of Magnetic Field Configuration on Thrust Performance in A Miniature Microwave Discharge Ion Thruster
}

Yamamoto, Naoji

Department of Advanced Energy Engineering Science, Kyushu University

Kondo, Shinya

Department of Advanced Energy Engineering Science, Kyushu University

Chikaoka, Takayuki

Department of Advanced Energy Engineering Science, Kyushu University

Nakashima, Hideki

Department of Advanced Energy Engineering Science, Kyushu University

他

http://hdl. handle. net/2324/14236

出版情報: Journal of Applied Physics. 102, pp. 123304-123304, 2007-12-19. American Institute of Physics

バージョン :

権利関係: Copyright 2007 American Institute of Physics. This article may be downloaded for personal use only. Any other use requires prior permission of the author and the American Institute of Physics. 


\title{
Effects of magnetic field configuration on thrust performance in a miniature microwave discharge ion thruster
}

\author{
Naoji Yamamoto, ${ }^{\text {a) }}$ Shinya Kondo, Takayuki Chikaoka, and Hideki Nakashima \\ Department of Advanced Energy Engineering Science, Kyushu University, 6-1 Kasuga-kouen, Kasuga, \\ Fukuoka 816-8580, Japan \\ Hirokazu Masui \\ Department of Electrical Engineering, Kyushu Institute of Technology, 1-1, Sensuicho, Tobata-ku, \\ Kitakyushu, Fukuoka, 804-0015, Japan
}

(Received 17 July 2007; accepted 23 October 2007; published online 19 December 2007)

\begin{abstract}
The effects of magnetic field configuration on thrust performance in a miniature microwave discharge ion thruster were investigated in order to improve thrust performance. First, the extracted ion beam current was measured for various levels of strength of the magnetic field. It was found that there is an optimum magnitude of the magnetic field. That this is due to the tradeoff between magnetic mirror confinement and microwave-plasma coupling was confirmed by measurement of the ion saturation current into the antenna of the ion thruster. The ion saturation current was found to decrease with an increase in magnetic field strength, due to the improvement in magnetic mirror confinement. The estimated electron temperature also decreases with an increase in magnetic field strength. This result shows that the increase in magnetic field strength leads to a decrease in microwave-plasma coupling. Next, the ion beam current for three magnetic field shapes was measured by changing the length of the central yoke. The results show that the optimum magnetic field shape depends on the mass flow rate because of the tradeoff between magnetic confinement and ionization probability. For the configurations tested, the $3 \mathrm{~mm}$ length central yoke is optimal for low mass flow, whereas $7 \mathrm{~mm}$ is the best for high mass flow. Overall, the extracted ion beam current is $21.4 \mathrm{~mA}$, at a xenon mass flow rate of $0.036 \mathrm{mg} / \mathrm{s}$, beam voltage of $1500 \mathrm{~V}$, and incident microwave power of 16 W. @ 2007 American Institute of Physics. [DOI: 10.1063/1.2822456]
\end{abstract}

\section{INTRODUCTION}

The demand for $\mathrm{mN}$-class miniature propulsion systems for small satellites is expected to grow in the future, since the adoption of small satellites, with their flexibility, short development time, and low cost, has been a breakthrough in space applications. ${ }^{1,2}$ Until recently, however, size restrictions have limited the capacity of the available propulsion systems.

An ion thruster is a rocket engine that works by pushing ions away from the spacecraft. The action of the ions leaving the thruster causes a reaction that pushes the spacecraft in the opposite direction. Ions produced in the discharge chamber can be propelled by an electric field. A pair of grids in the ion thruster accelerates the ions to very high speed, such as $30000-80000 \mathrm{~m} / \mathrm{s}$, and shoots them out of the thruster. Ion thrusters show high energy transfer efficiency, exceeding $70 \%$, with good specific propellant consumption. ${ }^{3}$ Therefore, ion thrusters have already been used extensively in space missions, such as Deep Space I, ${ }^{4}$ HAYABUSA, ${ }^{5,6}$ and others. ${ }^{\text {? }}$

The use of ion thrusters will expand the range and capabilities of small satellites; ${ }^{1,8}$ missions such as Mars exploration would become possible, as would satellite self-disposal. Miniature ion thrusters can also be used for precise highstability attitude and position control in large spacecraft, as well as for primary propulsion of microsatellites. Several studies have been conducted on the miniature ion

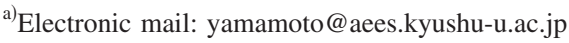

thruster. $^{9-14}$ Wirz et al. showed good performance of a 30 $\mathrm{mm}$ miniature xenon ion (MiXI) thruster, that is, the propellant utilization and the ion beam production cost were 0.8 and $500 \mathrm{~W} / \mathrm{A}$, respectively, for a mass flow rate of 0.02 $\mathrm{mg} / \mathrm{s}^{9}$ An electron bombardment-type ion source was used for ion production, so that operation time was limited by the thermionic cathode lifetime. A microwave discharge ion source would offer a potentially longer thruster lifetime, since the microwave discharge type would be free from contamination and degradation of the electron emission capacity.

The thrust performance of miniature microwave discharge ion thrusters has thus far been inferior to that of conventional ion thrusters, as poor microwave-plasma coupling, as well as large plasma losses from ion and electron collisions with the walls, has kept the cost of ion production very high. ${ }^{10,11}$ This type of ion source has a virtual cathode, ${ }^{15}$ a magnetic tube formed by a magnetic circuit, and an antenna to emit microwaves. ${ }^{16}$ Trapped electrons gain energy from the microwaves by electron cyclotron resonance (ECR) heating, and ionize neutral atoms while undergoing reciprocating motion between magnetic mirrors. Therefore, most of the ionization occurs in the magnetic tube. For effective microwave-to-plasma energy transfer, the antenna has to contact the ECR layer, since a strong electric field appears in the vicinity of the antenna. Of course, magnetic mirror confinement in the magnetic tube also affects the performance of the ion source. 


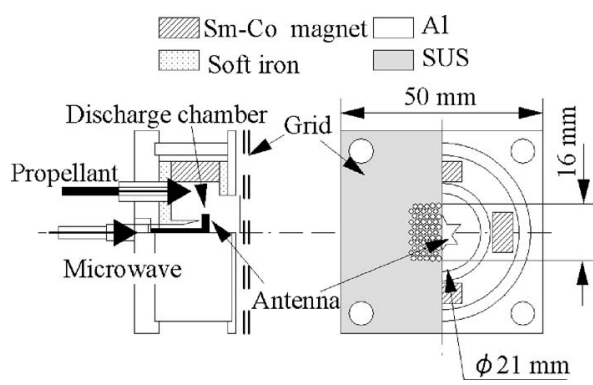

FIG. 1. Cross section of $50 \mathrm{~W}$ class miniature microwave discharge ion thruster developed at Kyushu University.

The aim of this study is to investigate the effects of magnetic field configuration on the thrust performance of the miniature microwave discharge ion thruster.

\section{EXPERIMENTAL EQUIPMENT}

\section{A. Thruster}

The cross section of a $50 \mathrm{~W}$ class miniature microwave discharge ion thruster is shown in Fig. 1. The inner diameter is $21 \mathrm{~mm}$ and the size of the thruster is $50 \times 50 \times 30 \mathrm{~mm}^{3}$. Flat square grids were used to extract the ion beam. The geometric parameters are shown in Table I. This geometry was designed using a numerical analysis code developed by Arakawa et al. ${ }^{17}$ The grid is made of molybdenum, and alumina cylinders are used as isolators between the two grids. The gap between the grids is $0.25 \mathrm{~mm}$ and the ion beam extraction area is $16 \times 16 \mathrm{~mm}^{2}$. The ion source consists of an antenna and a magnetic circuit, which is made up of several samarium cobalt ( $\mathrm{Sm}-\mathrm{Co})$ permanent magnets and iron yokes. The magnetic field profile of this thruster with nine Sm-Co magnets (calculated using QuickField 3.4, ${ }^{18}$ Tera Analysis Co.) is shown in Fig. 2. The magnetic field strength in the discharge chamber can be changed by changing the number of magnets, $N_{\text {mag }}$, as shown in Fig. 3. The magnetic flux density at the antenna center is increased with an increase in the number or magnets. A star-shape antenna was used, since it was shown in a previous study to perform well. ${ }^{9}$ The antenna is $1 \mathrm{~mm}$ thick. The antenna lifetime may not be an important challenge for this thruster, since the neutralizer adopted in HAYABUSA has an antenna and demonstrated its lifetime in excess of $15000 \mathrm{~h}^{19}$ The tip of the antenna is inserted into the magnetic tube formed by the magnetic circuit, as shown in Fig. 2. Microwave power at $2.45 \mathrm{GHz}$ was fed through a coaxial line and into the an-

TABLE I. Grid parameters.

\begin{tabular}{lccc}
\hline \hline & Screen & Acceleration \\
\hline Open area ratio (\%) & 51 & & 16 \\
Hole diameter (mm) & 0.90 & & 0.50 \\
Potential (V) & 1500 & -300 \\
Thickness (mm) & & 0.30 & \\
Hole pitch (mm) & 1.20 \\
Material & \multicolumn{3}{c}{ Molybdenum } \\
Grid gap (mm) & 0.20 \\
No. of holes & 211 \\
\hline \hline
\end{tabular}

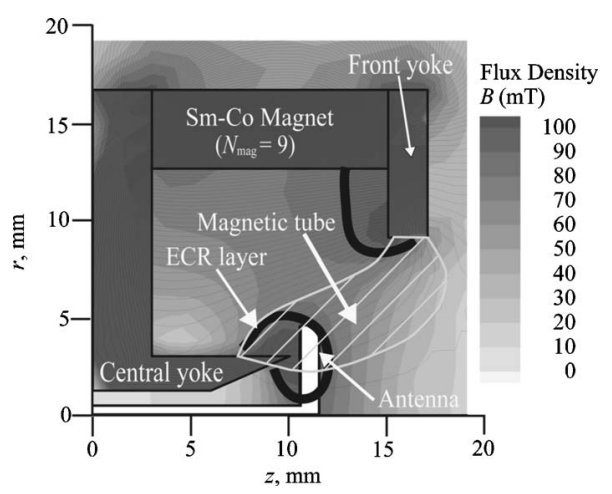

FIG. 2. Magnetic field profile of miniature ion thruster. $N_{\mathrm{mag}}=9$.

tenna. A dc block with a loss of $0.43 \mathrm{~dB}$ at $2.45 \mathrm{GHz}$ was inserted to protect the microwave amplifier, as shown in Fig. 4. The screen grid and ion source were biased to $+1500 \mathrm{~V}$ with respect to ground and the acceleration grid was set to $-300 \mathrm{~V}$. The extracted ion beam was estimated as the current through the screen power supply minus the current through the accelerator power supply. The validity of this method was shown in our previous study. ${ }^{20}$

No neutralizer was used in this study, as there is little difference between the extracted ion beam current without neutralizer and that with the filament neutralizer $(0.2 \mathrm{~mm}$ diameter $\times 100 \mathrm{~mm}$ length, $2 \%$ thoriated tungsten). There are, in fact, several candidate neutralizers for this thruster, including a field emission cathode, ${ }^{21,22}$ a filament cathode, an internal conduction cathode, ${ }^{23}$ and a microwave discharge cathode. ${ }^{24,25}$ A miniature microwave discharge neutralizer is under development, although it has thus far shown poor performance, ${ }^{24}$ with an electron current of $15 \mathrm{~mA}$ for an incident microwave power of $4 \mathrm{~W}$ and xenon mass flow rate of $0.005 \mathrm{mg} / \mathrm{s}$.

Thrust of the ion thrusters, $F$, can be estimated as

$$
F=\gamma_{T} I_{b} \sqrt{\left(2 m_{i} V_{b} / e\right)} \text {. }
$$

Here, $\gamma_{T}, I_{b}, m_{i}, V_{b}$, and $e$ are the thrust coefficient, extracted ion beam current, ion mass, beam voltage, and electronic charge, respectively. Considering the exhaust-beam divergence and the effect of doubly charged ions, $\gamma_{T}$ is defined as

$$
\gamma_{T}=\cos \theta_{b} \times(1+\alpha / \sqrt{2}) /(1+\alpha) .
$$

$\theta_{b}$ and $\alpha$ are the beam divergence angle and the ratio of the doubly charged ion current to the singly charged ion current, respectively. $\alpha$ and $\theta_{b}$ are assumed to be 0.15 and $10 \mathrm{deg},{ }^{26,27}$

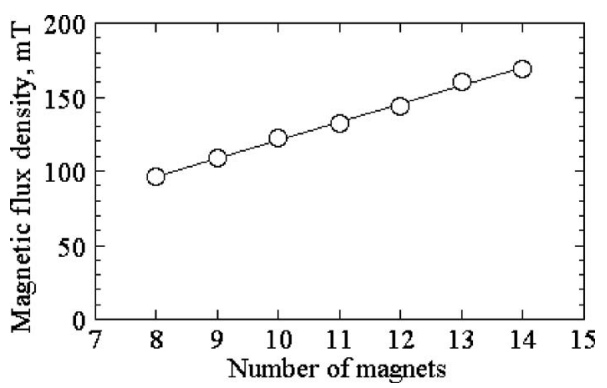

FIG. 3. Dependence of magnetic flux density at the antenna center on the number of magnets. 


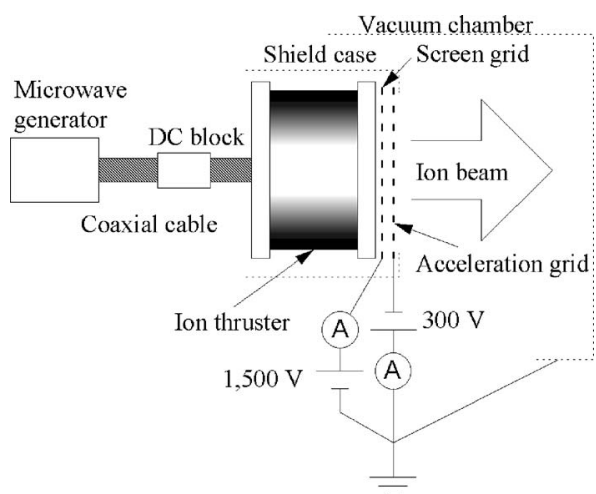

FIG. 4. Schematic of electric circuit.

respectively. Thus, in this study, $\gamma_{T}$ is estimated as $\gamma_{T}$ $\approx 0.98 \times 0.96=0.94$. The thrust of the ion thruster is proportional to the ion beam current with constant beam voltage. Hence, the extracted ion beam current is a good indicator for evaluating the thrust performance of the ion thrusters. The validity of this thrust estimation has been shown. ${ }^{6}$

High-purity (99.999\% pure) xenon gas was used as the propellant. A thermal mass flow controller (full scale $=0.29 \mathrm{mg} / \mathrm{s}$ ) with a flow accuracy of $\pm 0.7 \%$ for rate and $\pm 0.2 \%$ full scale (F.S.) was used to control mass flow rate, $\dot{m}$. For measurement of the loss at the antenna, the ion saturation current into the antenna was measured. To apply dc voltage to the antenna, bias- $T$ was used to separate direct current from $\mathrm{rf}$ current. The insertion loss of bias- $T$ is $0.4 \mathrm{~dB}$ and the maximum bias voltage and the maximum microwave power are $30 \mathrm{~V}$ and $10 \mathrm{~W}$, respectively. However, the ion currents are not saturated at $-30 \mathrm{~V}$, as shown in Fig. 5. Therefore, since the antenna can be treated as a planar electrostatic probe, the ion saturation current into the antenna was estimated as follows:

$$
I_{\mathrm{an}}=I_{\mathrm{io}}+I_{\mathrm{eo}} \exp \left\{-\frac{\left(\phi_{p}-V_{\mathrm{bi}}\right)}{T_{e}}\right\},
$$

where $I_{\mathrm{an}}$ is the current into the antenna, $I_{\text {io }}$ is the ion saturation current, $I_{\mathrm{eo}}$ is the electron saturation current, $\phi_{p}$ is the plasma potential, $V_{\mathrm{bi}}$ is the bias voltage against the discharge chamber, and $T_{e}$ is the electron temperature in the vicinity of the antenna. Indeed, there is little difference between curve fit and the experimental data, as shown in Fig. 5. The extracted grids were revised in order to maintain performance for incident microwave power less than $10 \mathrm{~W}$. The geometric parameters are shown in Table II. The ion beam diameter is

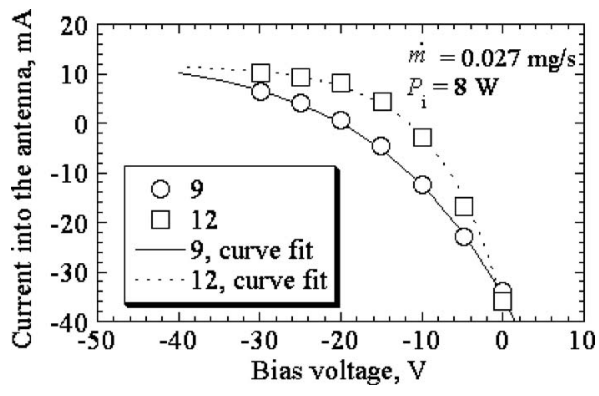

FIG. 5. Ion current into antenna vs bias voltage.
TABLE II. Revised grid parameters.

\begin{tabular}{lcc}
\hline \hline & Screen & Acceleration \\
\hline Open area ratio (\%) & 51 & 16 \\
Hole diameter (mm) & 1.20 & 0.70 \\
Potential (V) & 1000 & -200 \\
Thickness (mm) & & 0.30 \\
Hole pitch (mm) & 1.50 \\
Material & \multicolumn{2}{c}{ Molybdenum } \\
Grid gap (mm) & 0.20 \\
No. of holes & \multicolumn{2}{c}{} \\
\hline
\end{tabular}

$16 \mathrm{~mm}$. The magnetic field profile is the same as that shown in Fig. 2.

\section{B. Vacuum chamber}

A $0.6 \mathrm{~m}$ diameter, $1 \mathrm{~m}$ long vacuum chamber was used in the experiments. The pumping system was comprised of a cryo-pump and a turbo molecular pump. The background pressure was maintained below $1.2 \times 10^{-3} \mathrm{~Pa}$ for most of the operating conditions.

\section{RESULTS AND DISCUSSION}

\section{A. Magnetic field strength}

Figure 6 shows the dependence of ion beam current on magnetic field strength for three mass flow rates. Incident microwave power is varied to obtain the same specific energy, i.e., incident microwave power per mass flow rate, for each mass flow rate.

The ion beam currents of $N_{\mathrm{mag}}=10,12$, and 14 are 11.2, 13.2 , and $12.1 \mathrm{~mA}$, respectively, at $\dot{m}=0.018 \mathrm{mg} / \mathrm{s}, V_{b}$ $=1500 \mathrm{~V}$, and $P_{i}=8 \mathrm{~W}$. That is, there is an optimum magnetic field strength. The maximum thrust achieved is 0.79 $\mathrm{mN}$, at $N_{\mathrm{mag}}=12$. A similar trend is seen for $\dot{m}$ $=0.027 \mathrm{mg} / \mathrm{s}$, although in that case the optimum $N_{\text {mag }}$ is 13 , and the thrust is estimated as $1.1 \mathrm{mN}$. This trend is due to the tradeoff between magnetic mirror confinement and microwave-plasma coupling; with increasing $N_{\text {mag }}$, the magnetic confinement is improved, so that the ion beam current increases with an increase in $N_{\text {mag. }}$. Plasma-microwave coupling deteriorates with an increase in $N_{\text {mag }}$ due to the increase in the distance between the antenna and the ECR layer, where the microwave power is absorbed efficiently, ${ }^{28}$ as shown in Fig. 7. Figure 8 shows the dependence of the reflection coefficient, $\Gamma$, on the number of magnets. $\Gamma$ is a good indicator of the degradation of the microwave-plasma coupling. $\Gamma$ 's with $N_{\text {mag }}=11,13$, and 15 are $0.14,0.15$, and 0.17 , respectively. That is, $\Gamma$ increases with an increase in $N_{\text {mag }}$, as mentioned above. Therefore, the microwave-plasma coupling deteriorates and the plasma cannot be ignited beyond $N_{\text {mag }}=16$ because the distance between the antenna and the ECR layer is too great.

In order to investigate the effect of magnetic field strength on the magnetic confinement, ion saturation current into the antenna was measured, since it can be evaluated as the loss on the antenna. The saturation current into the antenna for several $N_{\text {mag }}$ for $\dot{m}=0.018 \mathrm{mg} / \mathrm{s}$ is shown in Fig. 9 . 


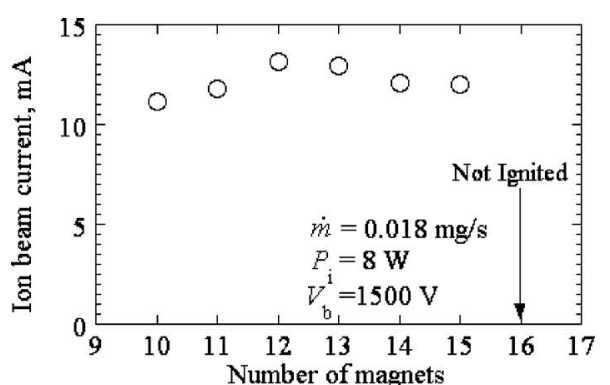

(a)

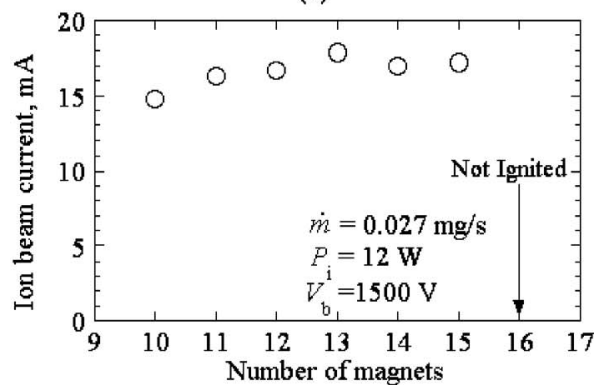

(b)

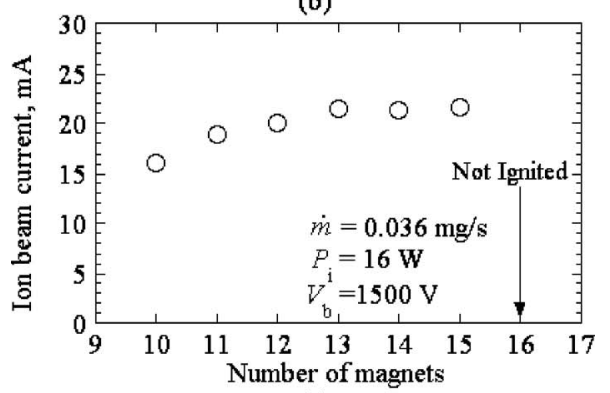

(c)

FIG. 6. Dependence of ion beam current on magnetic field strength. (a) $\dot{m}$ $=0.018 \mathrm{mg} / \mathrm{s}, P_{i}=8 \mathrm{~W}, V_{b}=1500 \mathrm{~V}$. (b) $\dot{m}=0.027 \mathrm{mg} / \mathrm{s}, P_{i}=12 \mathrm{~W}, V_{b}$ $=1500 \mathrm{~V}$. (c) $\dot{m}=0.036 \mathrm{mg} / \mathrm{s}, P_{i}=16 \mathrm{~W}, V_{b}=1500 \mathrm{~V}$.

The ion saturation currents into the antenna for $N_{\text {mag }}=9,10$, 11 , and 12 are $23,13,15$, and $11 \mathrm{~mA}$, respectively. That is, the ion saturation current, i.e., the loss on the antenna, decreases with an increase in $N_{\mathrm{mag}}$. This means that the plasma in the vicinity of the antenna is pushed farther from the antenna as the magnetic flux density at the antenna increases. These results show the validity of the assumption that an increase in the magnetic field strength leads to an improve-

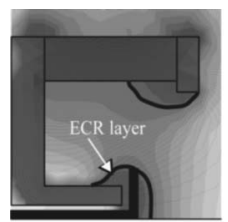

(a)

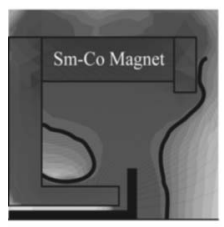

(c)

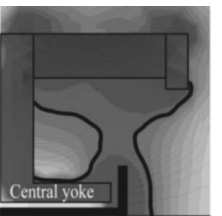

(b)

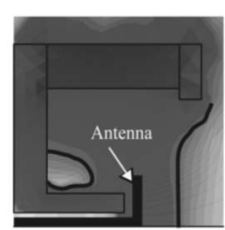

(d)
Flux Density $B(\mathrm{mT})$

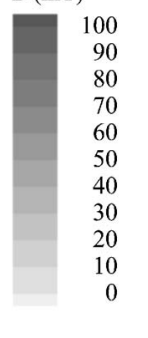

FIG. 7. Magnetic field profile for each $N_{\text {mag. }}$ (a) $N_{\text {mag }}=10$, (b) $N_{\text {mag }}=12$, (c) $N_{\text {mag }}=14$, and (d) $N_{\text {mag }}=16$.

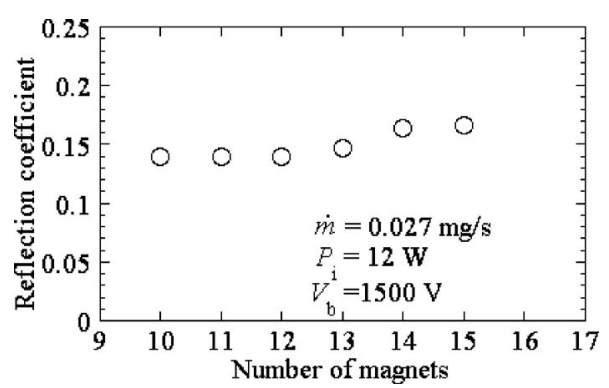

FIG. 8. Dependence of reflection coefficient on magnetic field strength at $\dot{m}=0.027 \mathrm{mg} / \mathrm{s}$ and $P_{i}=12 \mathrm{~W}$.

ment in magnetic mirror confinement. The decrease in loss leads to an increase in the extracted ion beam current, that is, the thrust.

The relation between the electron temperature in the vicinity of the antenna and the number of magnets was investigated. The estimated electron temperatures of $N_{\mathrm{mag}}=9,10$, 11 , and 12 are $29,20,16$, and $11 \mathrm{eV}$, respectively. That is, the electron temperature decreases with an increase in $N_{\text {mag. }}$. These results show the validity of the assumption that an increase in the magnetic field strength leads to a deterioration in microwave-plasma coupling.

As shown in Fig. 6, the ion beam currents for $N_{\text {mag }}=11$, 13 , and 15 are $18.9,21.4$, and $21.6 \mathrm{~mA}$, respectively, at $\dot{m}$ $=0.036 \mathrm{mg} / \mathrm{s}$. That is, the beam current increases with the number of magnets, and the ion current saturates above $N_{\text {mag }}=13$. This trend is different from the cases with $\dot{m}$ $=0.018$ and $0.027 \mathrm{mg} / \mathrm{s}$. This is because plasma density is high enough at $\dot{m}=0.036 \mathrm{mg} / \mathrm{s}$ that the low level of coupling is less significant than in the $\dot{m}=0.018$ and $0.027 \mathrm{mg} / \mathrm{s}$ cases.

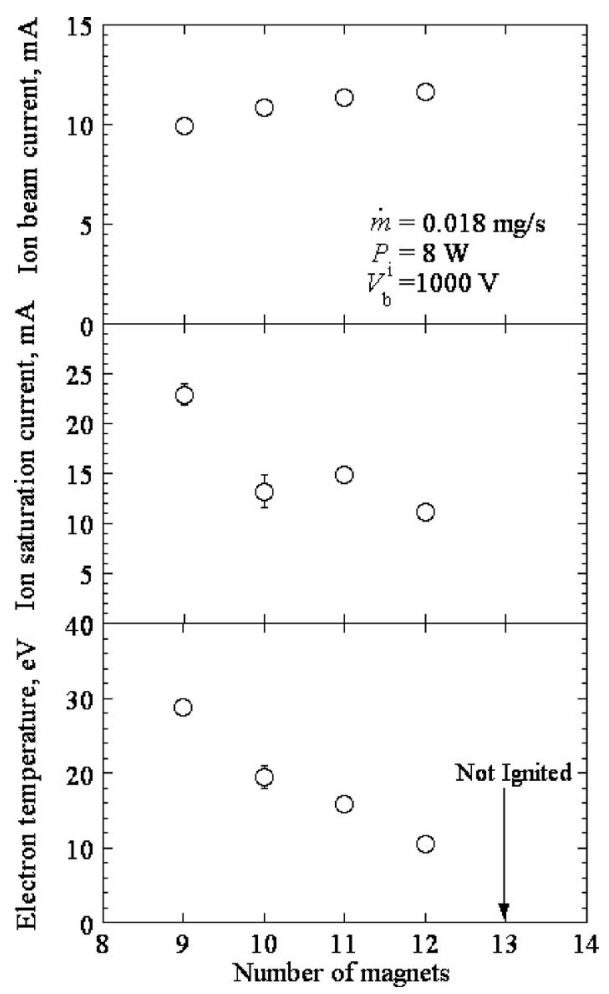

FIG. 9. Dependence of saturation current and electron temperature on magnetic field strength at $\dot{m}=0.018 \mathrm{mg} / \mathrm{s}$ and $P_{i}=8 \mathrm{~W}$. 


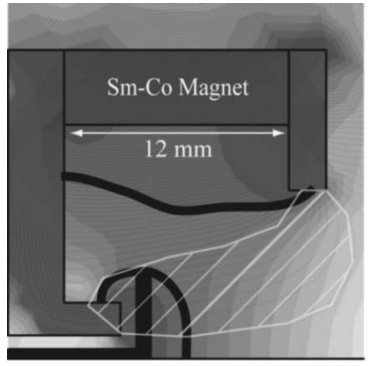

(a)

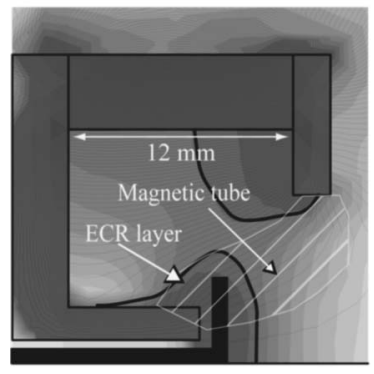

(c)

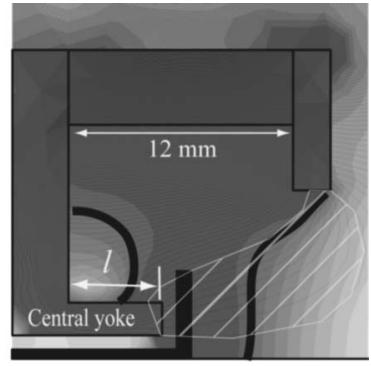

(b)

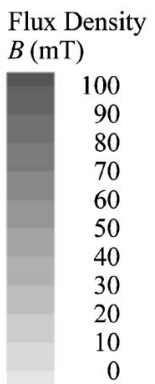

G. 10. Magnetic field profile for each central yoke length. (a) $l=3 \mathrm{~mm}$, $N_{\text {mag }}=11$. (b) $l=5 \mathrm{~mm}, N_{\text {mag }}=13$. (c) $l=7 \mathrm{~mm}, N_{\text {mag }}=10$.

\section{B. Magnetic field shape}

The effect of magnetic field shape was investigated, with the objective of extending the magnetic tube, i.e., enlarging the volume of the ionization zone, as shown in Fig. 10. This will lead to an improvement in the thrust performance of the thruster. The central magnetic yoke length was changed for a constant chamber length. Figure 11 shows the dependence of the ion beam current on the central yoke length, $l$. The number of magnets is optimized for each case. At $\dot{m}$ $=0.018 \mathrm{mg} / \mathrm{s}$ and $P_{i}=8 \mathrm{~W}$, the ion beam currents for $l=3$,

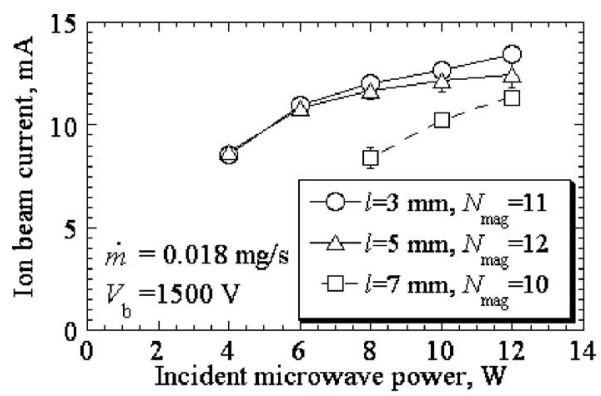

(a)

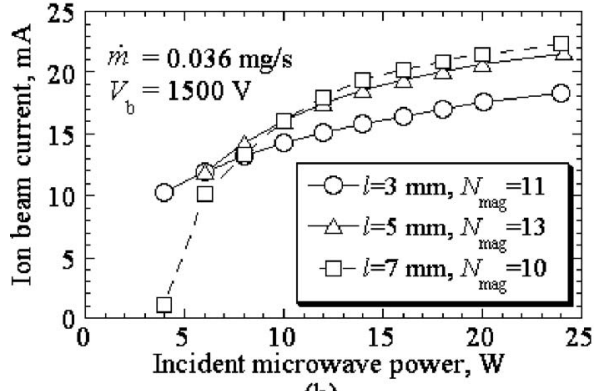

(b)

FIG. 11. Dependence of ion beam current on central yoke length. (a) $\dot{m}$ $=0.018 \mathrm{mg} / \mathrm{s}$. (b) $\dot{m}=0.036 \mathrm{mg} / \mathrm{s}$.
5, and 7 are 12.1, 11.6, and $8.4 \mathrm{~mA}$, respectively. That is, the beam current increases with a decrease in $l$, due to the enlargement of the ionization zone.

At $\dot{m}=0.036 \mathrm{mg} / \mathrm{s}$ and $P_{i}=16 \mathrm{~W}$, the ion beam currents for $l=3,5$, and 7 are 17.6, 19.4, and $20.2 \mathrm{~mA}$, respectively. That is, the ion beam current increases with an increase in $l$. This reversal is due to the effect of the improvement in confinement, which exceeds the effect of the reduction in the volume of the ionization zone. The thrust performance is thus improved. The results show that the optimum central yoke length depends on the mass flow rate because of the tradeoff between magnetic confinement and ionization probability. For the configurations tested, the $3 \mathrm{~mm}$ length central yoke is the best for low mass flow rates, whereas $7 \mathrm{~mm}$ is the best for high mass flow rates.

\section{CONCLUSION}

The effects of magnetic field configuration on the thrust performance of a $50 \mathrm{~W}$ class miniature microwave discharge ion thruster were investigated.

(1) Thrust was measured for several magnetic field strengths in the discharge chamber. The thrusts for $N_{\mathrm{mag}}=10,12$, and 14 are $0.67,0.79$, and $0.73 \mathrm{mN}$, respectively, at a xenon mass flow rate of $0.018 \mathrm{mg} / \mathrm{s}$, incident microwave power of $8 \mathrm{~W}$, and beam voltage of $1500 \mathrm{~V}$. There is an optimum magnetic field strength that depends on the mass flow rate because of the tradeoff between the microwave-plasma coupling efficiency and the magnetic mirror confinement. Experimental results validate this assumption: the ion saturation current into the antenna, i.e., loss on the antenna, decreases with an increase in $N_{\text {mag }}$ due to the improvement in magnetic mirror confinement. The estimated electron temperature also decreases with an increase in $N_{\text {mag }}$, due to the degradation of microwave-plasma coupling.

(2) The ion beam current was measured for several magnetic field shapes by changing the central yoke length. At a mass flow rate of $0.018 \mathrm{mg} / \mathrm{s}$ and incident microwave power of $8 \mathrm{~W}$, the thrusts were $0.73,0.70$, and 0.50 $\mathrm{mN}$ for central yoke lengths of 3,5 , and $7 \mathrm{~mm}$, respectively. At a mass flow rate of $0.036 \mathrm{mg} / \mathrm{s}$, the thrust were $1.1,1.2$, and $1.2 \mathrm{mN}$, respectively. The results show that the optimum central yoke length depends on the mass flow rate because of the tradeoff between magnetic confinement and ionization probability.

Overall, the thrust in the miniature microwave discharge ion thruster is $1.3 \mathrm{mN}$, at a xenon mass flow rate of 0.036 $\mathrm{mg} / \mathrm{s}$, beam voltage of $1500 \mathrm{~V}$, and incident microwave power of $16 \mathrm{~W}$, with a $16 \times 16 \mathrm{~mm}^{2}$ extracted area.

\section{ACKNOWLEDGMENTS}

The present work was supported by a Grant-in-Aid for Scientific Research (C)(2), No. 16560691, and a Grant-inAid for Young Scientists (B), No. 17760638, sponsored by the Japan Society for the Promotion of Science, Japan.

${ }^{1}$ J. Mueller, Prog. Astronaut. Aeronaut. 45, 45 (2000). 
${ }^{2}$ M. Kato, S. Takayama, U. Nakamura, K. Yoshihara, and H. Hashimoto, IAC Paper No. 05.B5.6.B.01 (2005).

${ }^{3}$ P. J. Wilbur, V. K. Rawlin, and J. R. Beattie, J. Propul. Power 14, 708 (1998).

${ }^{4}$ J. S. Sovey, V. K. Rawlin, and M. J. Patterson, J. Propul. Power 17, 517 (2001).

${ }^{5}$ A. Fujiwara, J. Kawaguchi, D. K. Yeomans, M. Abe, T. Mukai, T. Okada, J. Saito, H. Yano, M. Yoshikawa, D. J. Scheeres, O. Barnouin-Jha, A. F. Cheng, H. Demura, R. W. Gaskell, N. Hirata, H. Ikeda, T. Kominato, H. Miyamoto, A. M. Nakamura, R. Nakamura, S. Sasaki, and K. Uesugi, Science 312, 1330 (2006).

${ }^{6}$ H. Kuninaka, K. Nishiyama, I. Funaki, T. Yamada, Y. Shimizu, and J. Kawaguchi, J. Propul. Power 23, 544 (2007).

${ }^{7}$ S. Kitamura, H. Nagano, Y. Nakamura, I. Kudo, and K. Machida, J. Propul. Power 2, 513 (1986).

${ }^{8}$ M. Kilter, Masters thesis, Luleå University of Technology, 2004.

${ }^{9}$ R. E. Wirz, Ph.D. dissertation, California Institute of Technology, 2005.

${ }^{10}$ N. Yamamoto, H. Masui, H. Kataharada, H. Nakashima, and Y. Takao, J. Propul. Power 22, 925 (2006).

${ }^{11}$ Y. Nakayama, I. Funaki, and H. Kuninaka, J. Propul. Power 23, 495 (2007).

${ }^{12}$ M. M. Tsay, Masters thesis, Massachusetts Institute of Technology, 2006.

${ }^{13}$ D. Felli, H. W. Loeb, K. H. Schartner, S. Weis, D. Kirmse, B. K. Meyer, R. Kilinger, H. Mueller, and D. M. Di Cara, IEPC Paper No. 2005-252 (2005).

${ }^{14}$ V. Mistoco, T. Trudel, S. Bilen, and M. Micci, IEPC Paper No. 2005-265
(2005).

${ }^{15}$ I. Funaki, H. Kuninaka, and K. Toki, J. Propul. Power 20, 718 (2004).

${ }^{16}$ H. Kuninaka and S. Satori, J. Propul. Power 14, 1022 (1998).

${ }^{17}$ M. Nakano, T. Tachibana, and Y. Arakawa, Trans. Jpn. Soc. Aeronaut. Space Sci. 45, 154 (2002).

${ }^{18} \mathrm{http} / / / \mathrm{ww}$.quickfield.com/.

${ }^{19}$ I. Funaki, S. Satori, and H. Kuninaka, Jpn. J. Appl. Phys., Part 1 37, 4228 (1998).

${ }^{20}$ Y. Takao, H. Kataharada, T. Miyamoto, H. Masui, N. Yamamoto, and H. Nakashima, Vacuum 80, 1239 (2006).

${ }^{21}$ Y. Okawa, S. Kitamura, S. Kawamoto, Y. Iseki, K. Hashimoto, and E. Noda, IAC Paper No. 05-C4.4.07 (2005).

${ }^{22}$ A. Yamamoto, H. Nakai, N. Kaneko, T. Nakashizu, S. Ohsawa, T. Sugimura, and M. Ikeda, Proceedings of the 2003 Particle Accelerator Conference, Vol. 3326 (IEEE, New York, 2003).

${ }^{23}$ R. Wirz, M. Gale, J. Mueller, and C. Marrese, AIAA Paper No. 2004-4115 (2004).

${ }^{24}$ M. Tanisho, H. Kataharada, N. Yamamoto, and H. Nakashima, IAC Paper No. 05-CIAC-05-C4.4.02 (2005).

${ }^{25}$ I. Funaki and H. Kuninaka, Jpn. J. Appl. Phys., Part 1 40, 2495 (2001).

${ }^{26}$ S. Satori, H. Kuninaka, and M. Otaki, J. Jpn. Soc. Aeronaut. Space Sci. 46, 406 (1998) (in Japanese).

${ }^{27}$ H. Takegahara, Y. Kasai, Y. Gotoh, K. Miyazaki, Y. Hayakawa, S. Kitamura, H. Nagano, and K. Nanamura, IEPC Paper No. 93-235 (1993).

${ }^{28}$ H. Masui, Y. Tashiro, N. Yamamoto, H. Nakashima, and I. Funaki, Trans. Jpn. Soc. Aeronaut. Space Sci. 49, 87 (2006). 